\title{
Whither community care?
}

\author{
PETER TYRER
}

The PRiSM psychosis study reported in this issue comes at an opportune time. Community care, despite its ambiguity and difficulties in definition, has been a cornerstone of policy for mental health services for the past half-century. In the past few years, however, confidence in the policy has faltered, largely because of adverse reports in the media. Scarcely a day goes by without a scandal alleging that it has failed fundamentally. Criticisms have also been made by influential commentators and practitioners who question the rationale and strategy of the policy as well as doubting its efficacy (Dedman, 1993; Coid, 1994).

\section{EFFICACYAND EFFECTIVENESS OF COMMUNITYCARE}

The 10 papers reported from PRiSM provide a comprehensive picture of all aspects of community care for 'severe mental illness', an unsatisfactory term that is still searching for a common definition (Schinnar et al, 1990), but which mainly refers to those who have persistent or recurring psychotic illness. The PRiSM team emphasise in their contributions that they are examining the effectiveness of community care for this population rather than its efficacy (Thornicroft et al, 1998, this issue). This distinction is becoming more apposite as evidence is increasing that many types of treatment that succeed under ideal experimental conditions do not do nearly as well when transferred to ordinary clinical circumstances. Comparisons of efficacy are best carried out using the mechanism of the randomised controlled trial and these have established that good community care offers definite advantages; what is far from certain is that these gains are generalisable to ordinary practice over a long time-scale.
Such longer term studies of effectiveness are less tainted by criticism that is sometimes made about some of the earlier research studies - that they are carried out by enthusiasts evaluating their own services.

\section{INTENSIVE AND STANDARD CASE MANAGEMENT AND ASSERTIVE COMMUNITY TREATMENT}

There has been extensive evidence that assertive community treatment is a useful and effective intervention. This was first demonstrated by the pioneering study of Stein \& Test (1980) and modifications of this, including other forms of intensive comprehensive care, have generally been shown to be more cost-effective compared with old-fashioned standard treatments for severe mental illness (Hoult \& Reynolds, 1985; Dean \& Gadd, 1990; Merson et al, 1992; Muijen et al, 1992). Although these are more expensive because they employ more staff, with case loads per worker sometimes being limited to 10 or less, the savings that are made on numbers and duration of psychiatric admission are more than enough to compensate for the extra expense (Santos et al, 1988; Burns et al, 1993).

Interpretation of the data is handicapped by the new etymology of community care. Case management was introduced in the US in the 1980s (Intagliata, 1982) and was embraced almost too lovingly by the mental health services (Onyett, 1992). It has been shown to have considerable disadvantages when administered in an inflexible and bureaucratic way and this is exemplified by the introduction of the Care Programme Approach and its bedfellow, care management, in England (Anonymous, 1995). Care (or case) management increases the number of admissions to hospital (Marshall \& Lockwood, 1998) and is generally profligate of re- sources (Tyrer et al, 1995; Tyrer, 1998). Intensive case management may be synonymous with assertive community treatment (and almost certainly was equivalent in the PRiSM study), but if there are external factors preventing the team working in an integrated fashion (such as management brokerage) differences start to appear.

The major finding of the PRiSM study that will reverberate uncomfortably in many quarters is that standard case management is at least as good as intensive case management in its general effects on symptoms and disability and for people with lower levels of impairment is sometimes superior (Wykes et al, 1998, this issue). As a natural consequence of this the cost advantages found in previous studies of intensive case management in its general effects on symptoms and disability and for people with lower levels of impairment is sometimes superior (Wykes et al, 1998, this issue). As a natural consequence of this the cost advantages found in previous studies of intensive case management and assertive community treatment were not shown in the PRiSM study. As admissions were similar in both teams intensive case management was significantly more expensive than standard management and offered no apparent advantages whatsoever.

\section{IMPACT OF COMMUNITY CARE ON OTHERS}

The main media criticism of community care for severe mental illness is that the problems of severe mental illness are imposed unfairly on other people, including care-givers such as relatives and society as a whole, and this is particularly unwelcome when it leads to violence or other forms of antisocial behaviour. The results of the PRiSM psychosis study suggest that both intensive and standard community care are effective in improving the lot of the average patient with a psychotic disorder and that no special advantages are offered by the intensive service. In fact, that is a somewhat paradoxical effect of the intensive service apparently creating increased dependence in those that are less psychotic and increasing rather than reducing the incidence of violence, this is the main single point of concern over community care. As far as the general community is concerned the old adage 'out of sight, out of mind' still applies. Most of us, even those of an 
altruistic bent, would prefer patients who are disturbed to be placed in an institution well away from us rather than disturbing our daily lives - even if (as is universally shown) they are more satisfied with living in the community than in hospital. The results of the PRiSM study and other models of community care show no intervention to be effective in preventing these negative impacts on society as a whole.

\section{COORDINATED CARE}

There is still a minority of our profession who would prefer the title of this editorial to be 'Wither community care' on the basis that it is now outmoded. The evidence suggests otherwise; it is relevant and effective but still has some rough edges and needs its proper share of resources (Lelliott et al, 1993). In particular it needs to address the proper concerns of the public about the incidence of violence and antisocial behaviour demonstrated by a small, but dangerous, minority of those with severe mental illness. What the PRiSM study has demonstrated is that the exact model of community care being offered, whether assertive, intensive or standard, is really unimportant. The key to the success lies in having a coordinated team approach to the care of the severely mentally ill in which each member has the requisite skills to intervene appropriately and at an opportune time to produce the maximum benefit. Supporting the team's skills is therefore more important than reducing the case loads of individual workers. Our preoccupation with the bureaucracy of care - case load size, care programme

PETER TYRER, FRCPsych, Imperial College School of Medicine. St Mary's Campus, Paterson Centre for Mental Health, 20 South Wharf Road, London W2 IPD

(First received 30 July 1998, accepted 17 August 1998)

levels, independent needs assessment - has prevented us from examining the more difficult task of what makes a team function badly or well, or in another sense, what allows it to be effective and assertive even if relatively deprived of resources? Good community care is alive and well, but needs stimulation and succour.

\section{REFERENCES}

Anomymous (1995) Care management: a disastrous mistake. Lancet, 345, 399-40I.

Burns, T., Raftery, J., Beadsmoore, A., et ol (1993) A controlled trial of home-based acute psychiatric services. II: Treatment patterns and costs. British journal of Psychiotry, 163, 55-61.

Coid, J. (1994) Failure in community care: psychiatry's dilemma. British Medical journal, 308, 805-806.

Dean, C. Eadd, E. M. (1990) Home treatment for acute psychiatric illness. British Medical journal, 301. $1021-1023$.

Dedman, P. (1993) Home treatment for acute psychiatric disorder. British Medical journal, 306. 1359-1360.

Hoult, J. \& Roynolds, I. (1985) Schizophrenia: a comparative trial of community-oriented and hospital oriented psychiatric care. Acta Psychiatrica Scandinovica, 69. 359-372.

Intagliata, J. (1982) Improving the quality of community care for the chronically mentally disabled: the role of case management. Schizophrenia Bulletin. 8. 655-674.

Lelliott, P., Sims, A. Wing, J. (1993) Who pays for community care? The same old question. British Medical journal, 307, 991-994.
Marshall, M. \& Lockwood, A. (1998) Assertive community treatment for people with severe mental illness. In The Cochrane Library, Issue 3. Oxford: Update Software.

Merson, S., Tyrer, P., Omyett, S., et al (1992) Early intervention in psychiatric emergencies: a controlled clinical trial. Loncet, 339, 1311-1314.

Muljen, M., Marks, I., Connolly, J., et al (1992) Home based care and standard hospital care for patients with severe mental illness: a randomised controlled trial. British Medical Journal, 304, 749-754.

Onyett, S. (1992) Cose Management in Mental Health. London: Chapman and Hall.

Santos, A. B., Thrasher, J. W. J. \& Ballenger, J.C. (1989) Decentralized services for public hospital patients: a cost analysis. Hospital and Community Psychiotry, 39, 827-829.

Schinnar, A. P., Rothband, A. B., Kanter, R., et of (1990) An empirical literature review of definitions of severe and persistent mental illness. American journal of Psychiatry, 147, 1602-1608.

Stein, L. I. \& Test, M. A. (1980) Alternative to mental hospital treatment. I: Conceptual model, treatment program and clinical evaluation. Archives of General Psychiotry, 36, 1073-1079.

Thornicroft, G., Strathdee, G., Phelan, M., et al (1998) Rationale and design. PRiSM Psychosis Study I. British journal of Psychiatry. 173, 363-370.

Tyrer, P. (1998) Cost-effective or profligate community psychiatry? British journal of Psychiotry, 172, 1-3.

—, Morgan, J., Van Horn, E., et ol (1995) A randomised controlled study of close monitoring of vulnerable psychiatric patients. Lancet, 345, 756-759.

Wyloes, T., Leese, M., Taylor, R., et al (1998) Effects of community services on disability and symptoms. PRiSM Psychosis Study 4. British journal of Psychiatry, 173. 385-390. 